outcomes, safety and tolerability profile of Stribild ${ }^{\circledR}$ in clinical practice.

Methods Retrospective monocentric analysis on HIV-1-infected patients, who started with or were switched to Stribild ${ }^{\circledR}$. The percentage of patients remaining free of therapeutic failure was estimated using the time-to-loss-of-virologic-response (TLOVR) algorithm, by intent-to-treat analysis.

Results We analysed the data of 197 patients (56 ART-naïve and 141 treatment-experienced patients). At the end of follow-up (median 33 months), $87.3 \%$ of treatment-naïve and $80.3 \%$ of treatment-experienced patients remained free of therapeutic failure. A total of 17 patients stopped treatment with Stribild ${ }^{\circledR}$, $5.4 \%(3 / 56)$ of them were treatment-naïve and 9.9\% (14/141) were treatment-experienced patients. The Stribild ${ }^{\circledR}$ therapy was discontinued in 2 because of VF, loss to follow-up in 4, and drug-drug interactions in 2 patients. Adverse events were in 7 $(3.6 \%)$ patients the reason to switch from therapy with Stribild ${ }^{\circledR}$ and further $2(1.0 \%)$ patients decided personally to switch. In two patients novel resistances in integrase-gene $(\mathrm{N} 155 \mathrm{H}$ and S119R) emerged. In one further patient with VF two novel mutations in the RT-gene were observed when compared to historical genotypic test result (V106I/M and M184V).

Conclusion In treatment-naïve patients effectiveness of Stribild ${ }^{\circledR}$ was consistent with data obtained in clinical trials. The safety and tolerability profile as well as resistance development confirmed clinical efficacy of Stribild ${ }^{\circledR}$ in a daily practice setting.

Disclosure of interest statement Heiko Jessen received honoraria related to speakers' activities and consulting from ViiV Healthcare, AbbVie Germany, Bristol-Myers Squibb and Gilead Sciences, grants from MSD Sharp and Dohme and ViiV Healthcare and an additional grant from Gilead Sciences for this study.

\section{P17.37 SAFETY AND EFFICACY OF ELVITEGRAVIR/COBICISTAT/ EMTRICITABINE/TENOFOVIR DISOPROXIL FUMARATE IN TREATMENT-NAÏVE JAPANESE PATIENTS WITH HIV-1 INFECTION}

K Yajima*, H Yagura, S Yukawa, K Hirota, M Ikuma, D Kasai, D Watanabe, Y Nishida, T Uehira, T Shirasaka. AIDS Medical Center, National Hospital Organization Osaka National Hospital

\subsection{6/sextrans-2015-052270.615}

Introduction Elvitegravir/Cobicistat/Emtricitabine/Tenofovir Disoproxil Fumarate $(\mathrm{E} / \mathrm{C} / \mathrm{F} / \mathrm{TDF})$, a single tablet regimen, is expected as a pillar of antiretroviral therapy. Although, there have been few reports on antiviral effects and adverse events in cases of its initial therapy among Asian patients.

Methods We retrospectively reviewed medical records of patients treated with a single tablet regimen $\mathrm{E} / \mathrm{C} / \mathrm{F} / \mathrm{TDF}$ once daily between May 2013 and October 2014. Patients with insufficient data and those with conditions such as chronic renal failure or viral hepatitis were excluded.

Results In the 106 subjects who received E/C/F/TDF: 99\% men, $31 \%$ viral load $(\mathrm{VL}) \geqq 100,000$ copies $/ \mathrm{mL}$ (c/mL). Median characteristics were: age $37 \mathrm{yrs}$, VL $4.85 \log _{10} \mathrm{c} / \mathrm{mL}$, CD4 count 260 cells $/ \mu \mathrm{L}$. Mean change in CD4 count at Week 48 was +247 cells $/ \mu \mathrm{L}, \mathrm{VL}-2.7 \log _{10} \mathrm{c} / \mathrm{mL}$. The serum creatinine level increased by $0.09 \mathrm{mg} / \mathrm{dL}$ : however, no further increase was seen during the observation period. There was no report of proximal renal tubulopathy including Fanconi Syndrome. Liver function tests and lipid markers demonstrated no significant changes. A total of 21 adverse events (AEs) were observed in 18 subjects (17.0\%). The most common AEs were neurologic symptoms (dizziness, headaches, vivid dreams etc.), which occurred in 12 subjects: although, the symptoms either disappeared or ameliorated within 4 weeks in all subjects. No single AE led to discontinuation of more than 1 subject showed renal dysfunction. Virologic failure with resistance occurred in $3.8 \%$.

Conclusion High virologic response was seen in patients receiving $\mathrm{E} / \mathrm{C} / \mathrm{F} / \mathrm{TDF}$. This regimen was well tolerated, and no unique AEs were occurred, compared to the previous reports. These data support the use of $\mathrm{E} / \mathrm{C} / \mathrm{F} / \mathrm{TDF}$ as a potential new regimen for initial treatment of Japanese patients with HIV-1 infection. Disclosure of interest statement Authors do not have any commercial or other association that might pose a conflict of interest.

\section{P17.38 PLASMA DRUG LEVELS OF NEVIRAPINE PREDICT VIROLOGICAL RESPONSE IN PATIENTS RECEIVING TREATMENT IN KENYAN HOSPITALS}

1,2 M Kimulwo*, 1,2RC Kitawi, 1,2RS Mwatelah, 1,3 R Aman, 1,3 G Masankwa, 1,4 B Ogutu, ${ }^{1} \mathrm{~J}$ Okendo, ${ }^{4} \mathrm{RM}$ Lwembe, ${ }^{2} \mathrm{M}$ Muigai, ${ }^{1,4} \mathrm{~W}$ Ochieng. ${ }^{1}$ Center for Research in Therapeutic Sciences, Strathmore University, Nairobi, Kenya; ${ }^{2}$ Institute of Tropical Medicine and Infectious Diseases, JKUAT, Kenya; ${ }^{3}$ African Centre for Clinical Trials, Nairobi, Kenya; ${ }^{4}$ Kenya Medical Research Institute, Nairobi, Kenya

\subsection{6/sextrans-2015-052270.616}

Introduction Treatment failure is a key challenge in the management of HIV-1 infection. We examined the association of nevirapine blood levels with virologic treatment outcome and adherence among Kenyan patients on antiretroviral therapy (ART).

Methods A cross-sectional study involving 58 subjects receiving nevirapine as part of ART regimen. Clinical, demographic and adherence data were captured using structured questionnaires. Five millilitres of EDTA blood was collected at 1, 4 and $24 \mathrm{~h}$ post-dosing and used for quantification of nevirapine levels using High-Performance Liquid Chromatography (HPLC). Plasma viral load was determined on $m 2000$ Abbott RealTime HIV-1 assay platform and used to determine virologic treatment failure (VF). Results Median duration of ART was 42 months and $43.1 \%$ of the patients had VF with a mean viral load of $4.24 \log _{10}$ copies. Measured at $1 \mathrm{hr}(\log 2.93, \mathrm{p}=0.003)$ and at $4 \mathrm{hrs}(\log 3.07$, $\mathrm{p}<0.001)$ post dosing, Nevirapine levels were significantly lower for VF than non-VF patients and were significantly associated with virologic response $\left(c^{2} \mathrm{p}<0.001\right)$. These nevirapine levels at $1 \mathrm{hr}\left(\mathrm{R}^{2}=0.218, \mathrm{p}=0.002\right)$ and at $4 \mathrm{hrs}\left(\mathrm{R}^{2}=\right.$ $0.156, \mathrm{p}=0.001$ ) were significantly and inversely correlated with same day VL in a Spearman's rho model. Up to $53.4 \%$, $24.1 \%$ and $22.4 \%$ of the patients had good, fair and poor adherence respectively, with adherence being significantly associated with plasma nevirapine levels at $1 \mathrm{hr}\left(\mathrm{c}^{2} \mathrm{p}=0.001\right)$ and at $4 \mathrm{hr}$ $\left(c^{2} p=0.021\right)$. No significant associations were found at $24 \mathrm{hrs}$ post nevirapine dosing.

Conclusion Majority of VF patients attained nevirapine levels in plasma that were significantly lower than non-VF patients. These patients were also more likely to have poor adherence than virologic responders with higher nevirapine levels. Suboptimal exposures to nevirapine may be mitigated partly by improving adherence support mechanisms. Additional investigations should focus on pharmacogenetics and other factors influencing optimal drug uptake in blood.

Disclosure of interest statement ISSTDR and IUSTI recognise the considerable contribution that industry partners make to professional and research activities. We also recognise the need for 